\title{
Innovative Technologies of Human Resource Management
}

\author{
S.N. Kaznacheeva, I.B. Bicheva, Zh.V. Smirnova*, E.A. Chelnokova

\begin{abstract}
Minin Nizhny Novgorod State Pedagogical University, Nizhny Novgorod, Russian Federation
\end{abstract} \\ *Corresponding author. Email: z.v.smirnova@mininuniver.ru
}

\begin{abstract}
The article deals with the scientific and theoretical provisions that reveal the essence of the concepts of "innovation" and "innovative technology". This analysis allowed the authors to identify the basic principles and sequence of the process of formation of the organization's personnel. It is especially noted innovative technologies that have a pronounced effect on the formation of the organization's personnel are considered. It is shown that innovative technologies have high potential and contribute to the prospective formation of personnel. Innovative technologies take into account the interests of employees in professional development and career advancement by stimulating professional initiatives, transforming individual innovations into a development mechanism, as well as the interests of managers in improving the efficiency of professional work and achieving the organization necessary competitiveness in the modern market. There are a conclusion about the importance of teaching innovative technologies at the stage of professional training with the aim of forming future specialists and managers of perspective thinking as a condition for improving the quality of education and personnel management. The importance of the participation of potential employers in this work is emphasized. The authors offer an introduction special courses, trainings on the practical mastery of modern innovative technologies to the content of vocational training.
\end{abstract}

Keywords: personnel, innovations, human resource management, organization personnel formation,

personnel formation principles, innovative personnel formation technologies

\section{INTRODUCTION}

Human resource management is one of the factors that provides a competitive advantage for a company [7, 32]. The use of innovative technologies in the process of human resource management is considered as a priority area of effective personnel management [20,31]. This is due to the fact that there are changes in legislation, the trend towards digitalization and accelerated development of technology $[11,12,19,25]$.

Among the innovations in the sphere of Human resource management a digital questionnaire has been used for preliminary selection of applicants, the implementation of a flexible work schedule, the possibility to work remotely and so on in the end 90-ies of the 20th century. At the same time, existing market barriers reduce the chances of achieving higher growth rates. First of all, this is the lack of maturity of managers in the sphere of personnel management. Company management often pays too much attention and funds to the development of the main production areas but the functions which are considered as "providing", including HR, develop according to the residual principle. A barrier is a low level of IT literacy among employees of Russian enterprises, especially in the regions. Some companies continue to use old methods, for example, printing resumes on paper. The other barrier is "patchwork" automation, which is expressed in the absence of a comprehensive digital development strategy for the HR sector or budget for the realization of such a strategy in Russian companies. Overcoming market barriers actualizes the transformation of the management process on an innovative basis. According to V.G. Taroyan, the innovative process of human resource management is «the sum of managerial actions aimed at creating and developing human resources that are necessary for the process of the company's innovative strategy» [24, c. 11].

The purpose of the article is a scientific and theoretical analysis of modern innovative technologies which provide the formation of the personnel of organization.

For the first time the concept of «innovation» was introduced by the Austrian scientist J. Schumpeter. By innovation, he understood «a change in order to introduce and use new types of consumer goods, new production, means of transport, markets and forms of organization in industry» [2, c. 61]. This term is defined more specifically in modern research. For example, R.A. Fathutdinov understands innovation as the end result of introducing an innovation with the goal of changing the management object and getting an economic, social, environmental, scientific, technical or other effect [17]. B. Santo notes the activity-oriented character of innovation, underlining that it is a socio-technical and economic process, leading, ultimately, to the creation of unique or best technical products or technologies [21]. In P.N. Zavlina, A.K. Kazantseva, L.E. Mindeli's works it is approved that innovation is the use the results of intellectual (scientific 
and technical) activities in a particular area of society aimed at improving the process of activity or its results [9]. F.F. Bezdudnyi, G.A. Smirnova, O.D. Nechaev also considers innovation as a process of realisation of a new idea in any areas of human life, aimed at meeting the existing needs in the market and revenue-producing activity [3]. A.V. Surin and O.P. Molchanov think that innovation the end result of creative activity, embodied in the form of new or improved products or technologies that are practically applicable and can provide certain social and economic needs of society [23].

A content analysis of research the concept of «innovation» allows us to conclude that this is a process that creates an innovation (innovation) and ensures its use to achieve the most effective development of a person, organization and society as a whole [1, 4, 9]. Formula of innovation "Innovation = Innovation + Achieved Efficiency" proposed by A.E. Yakovlev and A.V. Plekhanov, opens up the role of scientific and technological progress and innovation in the modern economy [28].

Thus, the achievement of the effective development of the organization is determined by using of technologies that comply with the signs of innovativeness and innovative development, namely, innovative technologies. In T.I. Gurova's research it is underlined the essence of innovative technologies in Human resource management from the point of view of «qualitatively new for the company and the industry in which it works, tools, technologies, means and methods of organizing labor activities which allow to rise its competitiveness and financial and economic performance» $[10, \mathrm{c.36}]$.

V.M. Golyanich and E.I. Kudryavtseva consider this concept from the perspective of an organized decision, system, procedure or management method that are significantly different from established practice and are used in this organization at first time. The authors emphasize the need to correlate novelty with management practices in this particular organization [8].

According to L.I. Pronyaeva and A.V. Ameline's opinion innovative management technologies are a system «easily transformable accorfing to market changes, which allows us to form effectively, use and develop the organization's human resources» $[18$, c. 90$]$.

\section{BACKGROUND}
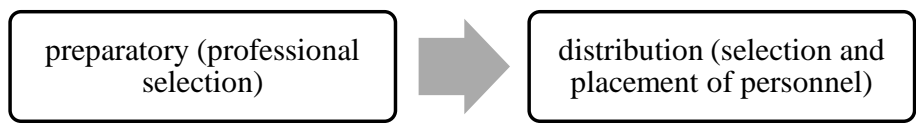

Because of the staff belongs to the most significant resource of the company, the application of innovative approaches to human resource management provides in the organization:

- a two-way process of interaction between the company and the staff;

- the effectiveness of the organization due to the ability of staff to improve and develop constantly;

- the long-term nature of the relationship between the employee and the employer by satisfying the aims of the employee agreed with the aims of the organization;

- favorable working conditions and the possibility of career growth for the staff, the necessary level of assurance in the future.

Some reaserchers underline it is necessary to have an innovative personnel management system to increase the effectiveness of the innovative development of the organization. This involves taking into account the following provisions:

- determination of common development strategies for the company and personnel, ensuring their interconnection;

- implementation of the peer review to measure to determine the level of impact of distribution cost to the staff and the economic level;

- development of the necessary and sufficient number of competencies and professional skills for the most successful work.

The main aim of staff formation in the company is to minimize losses in case of a discrepancy of the staff ability to do their activities with the possibilities of their use in performing specific types of work. Therefore, the process of staff formation should be based on the following principles:

- compliance principle, reflecting the ratio of the number of employees to the volume of work performed and their qualifications, the level of complexity of labor functions; the personnel structure of the company taking into account objective factors of production;

- the principle of continuity aimed at creating conditions for continuous further training and expanding the professional profile of employees;

- the principle of efficiency, determining the maximum use of working time.

Human resource management is a sequential process and consists of three stages (Figure 1).

Because of innovation is one of the elements of progress, innovative Human resource management is carried out at every stage. Personnel training and development are priority areas for modern business, which actualizes the use of innovative technologies

Figure 1. The stages of staff formation

The selection of innovative technologies is based on personnel decisions at various stages of personnel formation (Figure 2).
Consider some promising innovative technologies which have a pronounced effect on the process of staff formation in the organization. 
Headhunting is one of the tools for recruiting staff, which implies access to need specialists directly and draining them for the customer company. Headhunting appeared in the United States in the mid-1940s, and in the 1970s became a very profitable type of business. Today, fees for this type of service are $30-40 \%$ of the annual income of a specialist.

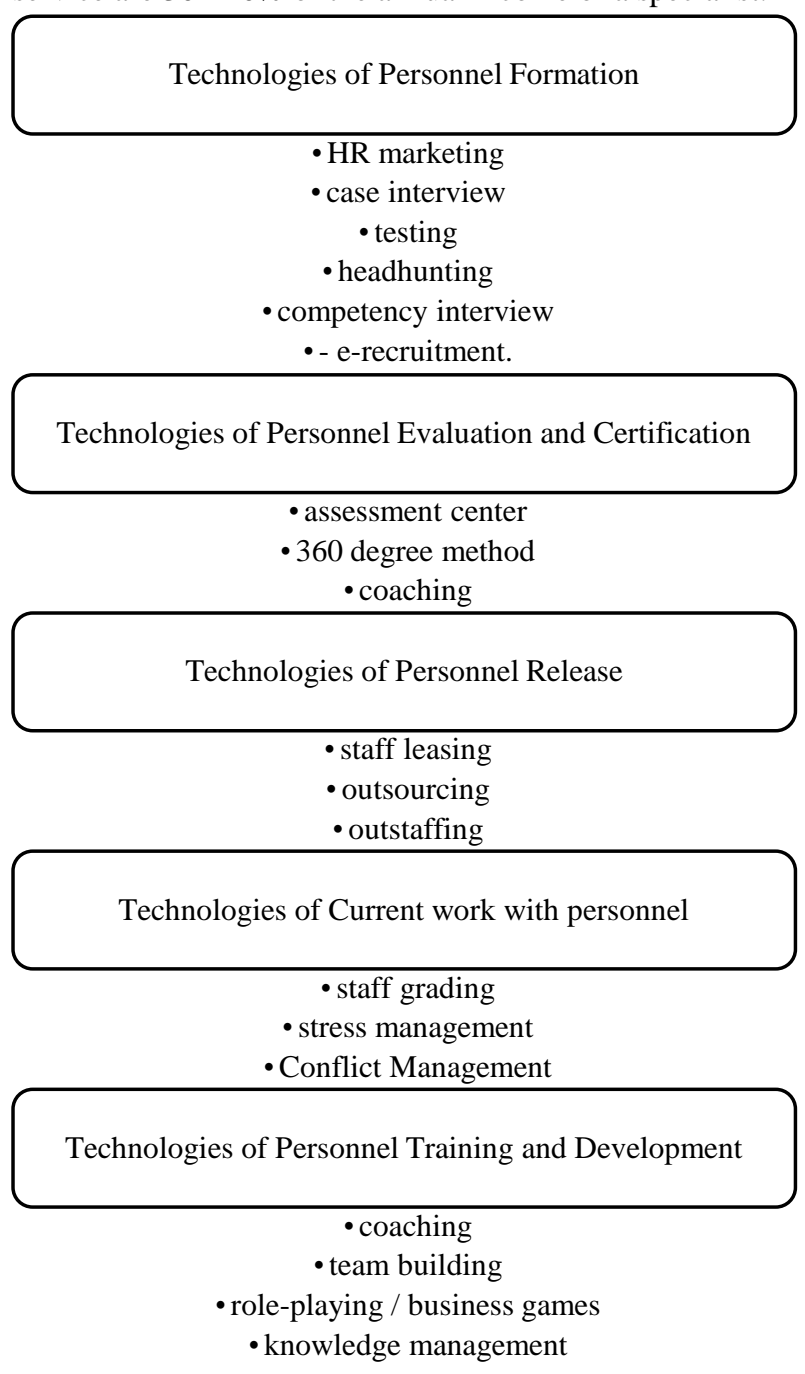

Figure 2. Innovative technologies of personnel formation

The use of headhunting is necessary if:

- the company becomes a market leader (the company has high turnover, a high level of competition, access to international markets);

- there is a confidential replacement of the top manager or the company cannot find a top manager on their own;

- the current manager decides to leave the company and it is necessary to find a replacement for him in a short time. E-recruitment. The growth of popularity of social networks (vkontakte.ru, odnoklassniki.ru, moikrug.ru) among young people has provoked the emergence of electronic recruiting [14]. Using social networks, the leadership manages to engage candidates who are not in the public domain. There are the following recruitment services:

- Potok-platform is designed to optimize recruitment and allows to create stages, teams and application forms for a specific vacancy. It is connected to career sites and social networks. Potok platform provides to create career site, a branded response form and the formation of the necessary reports. Project developers test an analytical platform which reads information about the behavior of potential recruits in social networks and reports when they will be ready to change jobs.

- Stafory is a recruiting service using freelancers. The platform allows to filter and choose offers, sort, store and export resumes of applicants, keep a calendar of interviews and meetings.

- Experium - a program is intended for automated recruitment by posting job advertisements on relevant sites, including social networks, sorting candidate cards, sending letters and SMS to candidates and so on.

- VCV-platform that allows to spend video interviews with applicants. The recruiter uploads a list of questions, response time to the system and sends them to the candidate, who answers to those questions onto video. The main advantage of the platform is to reduce the time for communication with candidates.

- AssessFirst - a platform aimed at the intelligent selection of personnel based on an analysis of the potential of employees, studying their motivation, capabilities and behavior.

Search ways for candidates in electronic recruiting are presented in Figure 3

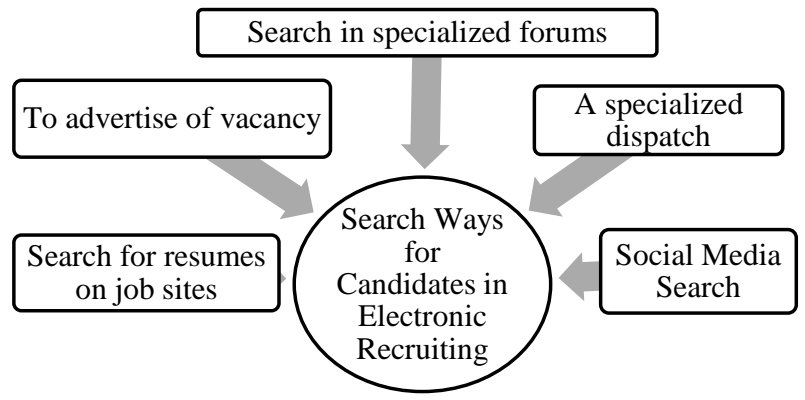

Figure 3. Search Ways for candidates in electronic recruiting

Assessment center is a conglomeration of methods for a comprehensive assessment of personnel according to specific customer tasks based on certain criteria (competencies). Assessment center has to identify the potential of the employee.

The effectiveness of this technology is significantly increased if it is organically included in the overall Human resource management. The getting data are become the basis for planning and organizing training in accordance with the stated standards, supported by motivational schemes.

The assessment method has the greatest efficiency in Human resource management, focused on internal and external communications (marketing, procurement, department heads). The technologies of the Assessment Center are "mail basket", "group discussions", "presentations", "labor tests", "case studies", etc.

The mail basket belongs to the classic exercise of the Assessment Center. This exercise simulates working with 
business correspondence of an employee who has begin to work in the organization or has been absent for several days at the workplace. There are from 15 to 20 different documents of different level of complexity and importance in the basket.

The technology of "group discussions" is used to assess leadership abilities and make decisions. The participants of the discussion (4-8 people) receive a task that they need to solve through the discussion. As a result, the group has to find a common decision.

The next technology - presentation - contributes to the development of rhetorical skills. The employee has to prepare a presentation on a specific topic and address the audience.

Labor tests are standardized methods in which professional tasks are imitated. Observers record participant behavior.

Case study or case method consists in the fact that each participant has material on a specific problem, for example, personnel, finance, organization structure, etc. The report is provided in writing. The advantage of this method is that the method can be adapted to the reality of the company.

Team Building occupies a special place in innovative technologies as an effective tool for improving communication and interaction between company employees. This technology is based on the idea of team methods and is borrowed from the sports world. Today, the following types of team building are used in management practice: sports, thematic, creative, psychological, intellectual.

Sports team building is one of the variants for effective team building in the process of organizing active sports competitions (team riding on bicycles, running, etc.).

Themed team building is effective if employees have common or similar work interests in the same team. This will allow to successfully organize and spend role-playing games, team competitions.

Creative team building is used to solve non-standard tasks and contributes to the development of the creative potential of employees, the generation of creative ideas in the process of interaction. For example, the aim of a creative team building may be to work together on one of the projects ("Coat of arms of our department", "Anthem of our company", etc.).

Psychological teambuilding is recommended if there are professional barriers or frequent conflict situations to find optimal solutions for team building and increase the level of confidence in each other and mutual understanding.

Intelligent team building is an effective way in order employees will be able to show their erudition, professionalism and creative abilities. The best variant for intellectual teambuilding is the game «What? Where? When?», intellectual quizzes and brain rings, where participants demonstrate their knowledge and also get new ones in informal atmosphere.

Personnel grading is a procedure for assessment and ranking posts. Positions are divided into groups (grades) according to their value for the company. Company DHL began to use Personnel grading in Russia in 1984. Later, companies Wimm-Bill-Dann, IBS and Rolf actively used this technology. The purpose of grading is to create a transparent wage grid that motivates employees to grow professionally and determine the value (value) of employees.

\section{CONCLUSION}

The corporate university technology allows to carry out one of the main motivational functions of personnel management influencing to the personal interests of employees, bringing them closer to the goals of the organization. Almost all large Russian companies have their own corporate universities. The leaders in corporate education are Sberbank, Gazprom Neft and Euroset in Russia.

The technology "career portal" has appeared recently. It is considered one of the tools that allows to inform employees of the organization about career opportunities, stimulating their professional development. The leadership of the company, in turn, has the opportunity to quickly and efficiently spread the word about career prospects inside the company. The advantages of this technology are corporate data retention and its management, a quick search for the necessary information, and the publication of the latest news. The "career portal" allows to do the exchange of information inside the organization easily and provides automation of individual personnel processes. The use of these innovative technologies allows the formation of staff competencies that meet current labor market requirements $[2,5,6,22,27]$.

So, the modern personnel management system has significant potential for innovative technologies. Their implementation is aimed at the process of staff formation in the organization and the future development of the organization itself. A feature of innovative technologies is a clear algorithm for researching innovation: the search for a new idea - the search for arguments and proof - the choice of alternative solutions (contributing to the achievement of a positive effect and addressing undesirable consequences). The need for more active application of innovative technologies in the personnel management system is caused by the opportunities that they provide. Firstly, innovative technologies quite fully take into account the interests of a particular employee in professional development and career advancement by stimulating professional initiatives, transforming individual innovations into a development mechanism. Secondly, they ensure the interests of managers in improving the efficiency of professional work and achieving the necessary competitive advantages by the organization and ensuring its competitiveness in the market. The actuality of the studying problem increases the significance of its solution not only in the field of personnel management in an organization.

In our opinion, a promising direction is the use of innovative technologies during the career guidance of students $[13,16$, 33 ] and at the stage of training of future specialists and managers $[30,34]$.

We think special courses and trainings training on practical issues of modern innovative technologies should be included into the content of vocational training. It will allow future specialists to form the necessary competencies 
[9]. Gokhberg L.M. Innovation as the basis of economic growth and strengthening Russia's position in the global economy, Bulletin of international organizations. 2012. No2. S. 101.

[10]. Gurova T.I. Innovative technologies in personnel management, Vestnik RMAT. 2017. No1. S.34-38.

[11]. Ermolaev E.Yu. The labor collective and the transformation of its activities in the process of establishing market relations: abstract. Dis ... Candidate of Economic Sciences: 08.00.01. Kazan 2006.24 s.

[12]. What will be the workplace in 2020? [Electronic resource]. URL: http://hr-elearning.ru/kakim-budetrabochee-mesto-v-2020-godu/ (Date of access: 12.20.2019)

[13]. Kaznacheeva S.N., Bystrova N.V., Urakova E.A., Sharygina E.N. Career guidance activities of the university in the modernization of the education system, Karelian Scientific Journal. 2019.Vol. 8. No. 2 (27). S. 31-34.

[14]. Kaznacheeva S.N., Repina R.V. Social networks in the modern world, Science of Krasnoyarsk. 2018.Vol. 7. No. 1-2. S. 44-48.

[15]. Kochetov A. N. Professional education and the labor market: problems of interaction, Sociology of Education. 2011. No. 8. S. 107-108.

[16]. Lerner P.S. Career guidance for schoolchildren as a factor in training personnel for a promising Russian economy, World of Education - Education in the World. 2009. No. 3. S. 3-13.

[17]. Porter M.E. Competitive advantages of countries [Electronic resource]. - URL: http: //economicus.ru/ise/Pdf_Z3/z3_art12_p308-356.pdf (Date of access: 12.20.2019)

[18]. Pronyaeva L.I., Amelina A.V. Modern innovative technologies in personnel management, Bulletin of state and municipal administration. 2016. No4. [Electronic resource] URL: https://cyberleninka.ru/article/n/sovremennyeinnovatsionnye-tehnologii-v-upravlenii-personalom (Date of access: 01/05/2020)

[19]. Razumova E. Innovation in HR. Analytical article on the results of the study. - URL http://hrmedia.ru/innovatsii-v-hr-analiticheskaya-statya-porezultatam-issledovaniya/ (Date of access: 12.20.2019)
[8]. Golyanich V.M., Kudryavtseva E.I. Innovative technologies in personnel management, Management Consulting. 2013. No. 2 (50). S. 5-16. 
[28]. Yakovlev A. E., Plekhanov A. V. Scientific and technological progress and innovation in the modern economy: textbook. allowance. Cheboksary: Publishing house of Chuvash. University, 2003.

[29]. Belinova, N.V., Bicheva, I.B., Krasilnikova, L.V., Khanova, T.G., Hizhnaya, A.V. The Role of Managerial Competence of an Executive in Improving the Quality of Pre-school Educational Organization (2020) Lecture Notes in Networks and Systems, 91, pp. 422-429.

[30]. Smirnova Zh.V., Kochnova K.A. Training of employees of service enterprises using information technologies, Vesknik of Minin University. 2019.Vol. 7. No. 1 (26). S. 5.31.

[32]. Kaznacheeva S.N., Chelnokova E.A., Bicheva I.B., Smirnova Z.V., Lazutina A.L. Worldwide management problems, Man in India. 2017.V. 97. No. 15. P. 191-199.

[33]. Kurbatova, AS; Bicheva, IB; Ivanova, NV; Zaitseva, SA; Krasilnikova, LV Career guidance problem as a systemic problem in Russian society REVISTA INCLUSIONES, Volume: 7 Pages: 158-173 Published: JAN-MAR 2020

[34]. Markova, S.M., Tsyplakova, S.A., Sedykh, C.P., Khizhnaya, A.V., Filatova, O.N. Forecasting the Development of Professional Education (2020) Lecture Notes in Networks and Systems, 91, pp. 452-459.
[27]. Shakun Yu.A. Professional competencies of employees as an instrument of organization competitiveness [Electronic resource]. URL: https://www.b-seminar.ru/article/show/93.htm (Date of access: 12/22/2019) 